RESENHA 



\title{
0 REGIME EPISTEMOLÓGICO DAS CIÊNCIAS HUMANAS NA FRANÇA CONTEMPORÂNEA
}

\author{
Manoel Ribeiro de Moraes Júnior (D)
}

Universidade do Estado do Pará 


\section{RESENHA}

Dosse, François. 2018. O Império do Sentido: $a$ humanização das Ciências Humanas. Trad. Ilka Stern Cohen. São Paulo: Ed. Unesp.

François Dosse (1950 - ) é um intelectual com formação acadêmica em História. Sua tese de doutorado intitulada L'école des Annales dans les médias depuis 1968, sob a orientação de Jean Chesneaux, já o direciona a um horizonte interdisciplinar e contemporâneo de investigação no palco da Nova História. Em nosso tempo, Dosse desenvolve suas atividades de investigação e docência na Université Paris-Est-Créteil-Valde-Marne e no Institut d'Études Politiques de Paris. Seus trabalhos como pesquisador e docente associaram sempre as esferas temáticas da Epistemologia e da história de pensadores e movimentos intelectuais contemporâneos, consecutivamente enfocando temas de pesquisa contidos no contorno das Ciências Humanas. De sua arrojada e numérica produção bibliográfica, pode-se destacar as seguintes obras: "Histoire du structuralisme”, “L’Empire du sens. L'humanisation des sciences humaines", "Paul Ricœur. Les sens d'une vie", "Michel de Certeau. Le marcheur blessé", "La Marche des idées. Histoire des intellectuels, histoire intellectuelle", "Le Pari biographique. Écrire une vie", "Michel de
Certeau. Entre le dire et le faire", "Paul Ricœur et les sciences humaines", "Gilles Deleuze et Félix Guattari, biographie croisée", "Castoriadis. Une vie, Paris" e "La Saga des intellectuels français". É importante notabilizar que seus trabalhos têm grande apreciação, inclusive decisiva, entre os/as pesquisadores/as brasileiros/as.

Tematicamente, os escritos de François Dosse têm uma envergadura temática ampla e, por isso, importante para o conhecimento e discussão da atual Ciências Humanas. Pessoas, pensamentos, épocas e livros ... Seu ponto de vista vai além da clássica tradição histórico-científica da França em consequência, claro, às veredas abertas pelas novas escolas intelectuais da história francesa após os movimentos de 1968. Suas ponderações realçam com destreza e brilhantismo assuntos sobre a História e sua cientificidade cotejadas continuamente aos desafios que lhes são contemporâneos. Esse binômio reflexão e crítica é resultado de uma interlocução que o autor tece entre a História, a Sociologia, a Antropologia e a Filosofia. Não é por menos. Tempo, consciência, memória, cientificidade, época, história, biografia e outros conceitos que constituem o estofo categórico da prática científica, segundo o próprio Dosse, são ainda pouquissimamente refletidos na tradição científica histórica em favor do exercício empírico-científico. 
Foi no IHTP (Institut d'Histoire du Temps PrésentInstituto de História do Tempo Presente), sob a direção de Henri Rousseau, que Dosse apreendeu a importância da reflexão epistemológica como algo sine qua non no exercício da investigação histórica. Esse fronte de reflexão/escrita lhe impulsionou para uma discussão circunscrita à epistemologia do "tempo presente" A obra L'empire du sens: l'humanisation des sciences humaines representa essa diligência do pensar a história do pensamento científico-humano num horizonte interdisciplinar e hodierno. Mas, não só, posto que Dosse perfaz essa historiografia consciente do dispositivo crítico de inspiração kantiana, ou seja, do princípio metódico que se pergunta sobre as possibilidades e os limites da práxis científica. Dessa forma, sob as suas inquietações, François Dosse afirma que o historiador não deve se ver só desafiado por seu tema de investigação, mas também por seus horizontes epistemológicos, o que justamente são os que estofam suas pragmáticas científicas.

A versão brasileira de "O império do sentido: a Humanização das Ciências Humanas", um trabalho traduzido por Ilka Stern Cohen, publicado em 2019 pela editora UNESP, mundaniza na lusofonia, na acepção heideggeriana, o importante trabalho de François Dosse sobre a prática contemporânea da História e de toda as Ciências Humanas - como já se afirmou, a partir do protagonismo (colaborativo) dos pensadores franceses. A delimitação que Dosse opta ao evidenciar os cientistas e filósofos euro-francófonos, não o faz perder de vista os movimentos mais globais dos intelectuais, das interlocuções disciplinares, das práticas científicas interdisciplinares e das rizomatizações (não cartográficas) dos saberes. Enfim, Dosse circula por grande parte dos temas contidos no ciclo integral das humanidades - ambiente intelectivo de múltiplos conhecimentos e de ramificações de saberes (Levy e Deleuze).

A obra tem um vigor documental, analítico, panorâmico e conclusivo de modo tematicamente intenso, mas sem perder o cenário do seu propósito fundamental: a diversidade da "pragmática cientifica" contemporânea. Dosse faz uma história atual das Ciências Humanas com um enfoque muito singular e com uma envergadura própria, tal como as dos grandes intelectuais desta área dos quais se destacam Koyré, Feyerabend, Kuhn, Stegmuller, Popper, Foucault, Russel, Reale e Zilsel. Dosse escreveu "O império do sentido" a partir dos jogos linguísticos e epistemológicos do próprio presente científico do qual ele faz parte.

Dosse dividiu a obra em nove sessões. Em cada uma delas, ele foca um horizonte contemporâneo de discussão epistemológica entre um ciclo específico de pensadores. É um par-delà tanto quanto ao positivismo documental ou factual nos estudos da 
História, quando ao próprio avanço aberto pela Escola dos Annales. Três dimensões poderiam ser destacadas neste horizonte investigativo de François Dosse: i) a cientificidade de uma história do presente; ii) que se interlocuciona com outras áreas das ciências; e iii) que, por último, se põe a uma contínua reflexão epistemológica da pragmática científica.

Por que essas questões se tornam tão patentes para Dosse na obra "O império do sentido"? Diferentes de muitos pensadores das ciências, o autor não instiga um conceito unificado de ciência. Mesmo enfocando pensadores franceses contemporâneos numa historiografia do presente, o leitmotiv dessa sua obra é cosmopolita e intensamente compreensiva, em concordância com Daniel Andler, para uma consecutiva apreciação crítica tanto das ciências europeias quanto da historiografia positivista. Por conseguinte, se dê destaque então a dois termos presentes no título e que são desenvolvidos em todo o livro com serenidade epistemológica e determinante discussão, são eles: o "sentido" e a "humanização".

Conflitos, protestos e reformulações ideológicas sobrevindos de "maio de 1968" provocaram uma atenção maior às questões dedicadas aos sentidos, às significações - dimensões de uma nova articulação intelectual que são concomitantemente política e científica, segundo Gauchet. Os pensadores contemporâneos se sensibilizaram a elas e, desta forma, assumiram posições não positivistas e não universalistas ( $a$ priori), às contingências antropológicas.

Essa virada não destinaria as Ciências Humanas ao ceticismo ou a um relativismo despropositado, mas sim a um vetor mais abrangente no qual o comportamento investigativo se desdobraria com maior atenção, autocrítica e sensibilidades às contingências das ações, aos sentidos próprios das experiências vividas. As ações e os sentidos de mundo agora seriam acolhidos como expressões autenticamente humanas, ou seja, práxis desprendidas por pessoas enquanto dimensão elementar do ser-conjunto, ou por grupos enquanto coletividade intersubjetiva. Se antes tais dimensões tinham suas idiossincrasias banalizadas, agora elas são consideradas aspectos tão diversos e, ao mesmo tempo, tão fundamentais para os estudos de casos e, por conseguinte, para a redimensionalidade da Epistemologia.

E, quanto ao termo da humanização, se estabelece o desafio de ampliação dos fazeres científicos atentos ao âmbito da cooperatividade - renunciando ao solipsismo da genialidade -, e o destacamento de um regime intelectual cônscio da pluralidade dos temas de pesquisa, das cooperações científicas (trabalhos investigativos acontecidos em rede) e das pertinentes e diversas existências 
das "oficinas da razão". As questões implicadas ao conceito de humanidade relembram ao cientista que sua dimensão existencial não o transpõe para um além privilegiado em relação a qualquer outra humanidade existente.

Nas nove partes do trabalho, as que agregam os 35 tópicos ou semicapítulos dispostos no livro, Dosse revela um novo regime de trabalho nas Ciências Humanas contemporâneas. Nelas, o leitor pode observar a existência de, ao menos, três forças motrizes que dinamizam os ciclos científicos das humanidades: o horizonte interpretativo das Ciências Humanas, a perspectiva analítica das ciências formais e o criticismo metodológico de inspiração filosófica. O que outrora poderiam ser vistos como fissuras intelectuais entre escolas de pensamento, Dosse as entende como vias interconectáveis para um fértil ambiente de investigação em que as ações de integrações sociais ou outras que acontecem a cargo da singularidade existencial, podem ser mais beminterpretadas e traduzidas conforme aspectos da capacidade humana de estabelecer continuamente ações e significações - em dinâmicas linguísticopragmáticas (Habermas) e dialógicas (Bakhtin).

Esses transbordamentos significativos levaram inclusive a uma condição trans-humana, sobretudo das discussões sobre o universo significativo de saberes e parentescos entre humanos e não humanos - com Latour e Callon contra Depuy. Essa ampliação se justificaria mais ainda quando se percebesse dois aspectos específicos às culturas, algo que podem ser entendidos com clareza durante o texto: 1) Na percepção do fato da descentralização dos pontos originários da razão, pelo menos no sentido sincrônico de Latour, e 2) Na condição reguladora da observação científica que favorecer percepção tteórica, o que favorece entender que as constituições sociais das representações e os tecidos conceituais das ações intersubjetivas têm alteridades específicas a um grau de pertencimento encarnado (ou não) de um determinado grupamento humano ao seu ambiente. Essa discussão, que parece ser exótica no instante em que se amplia a percepção da dinâmica intelectual de uma cultura como algo emergente de corpos socializantes, pensantes e linguisticamente interligados ao que se é amplamente, à natureza, ainda pode ser restringido ou censurado aos intelectuais ainda afeitos ao antropocentrismo positivista e ascético.

Sentido e política são as macrodimensões a partir das quais este livro se desdobra, do escritor ao leitor. Mesmo que François Dosse seja um historiador, sua escrituralidade esclarece a Epistemologia contemporânea no campo das Ciências Humanas ao centro daquilo que Hegel diria ser o "conceito". A revolução de maio de 1968 
não foi somente contra as forças autoritárias do Estado em relação à sociedade civil, mas também contra as pressões desumanas de um Estado nacional contra os imigrantes. Este livro é uma reflexão epistemológica que revela um autor cônscio dos desafios abertos às ciências para uma integração global equânime e democrática. É sob essas provocações que Dosse pensa os sentidos/as significações como elementos a serem enfocados na história, nas Ciências Sociais, nas ciências da linguagem, na Filosofia, nas ciências cognitivistas e ademais, como um debate de reconhecimento das alteridades. A humanização das Ciências Humanas faria então com que o pensamento científico não se coloque mais na posição de transcendência em relação aos outros saberes, e que também não veja a si mesmo como atividade presa à monolítica, unilateral e restrita ambivalência ocidental “Sociedade Civil/Estado” (Levy, Ricoeur, Noiriel).
Ainda na esteira da política e dos sentidos plurais, Dosse destaca que as Ciências Humanas devem se envergar às tradições e as suas diversas dimensões temporais e socioculturais, como uma advertência aos tempos pré-críticos de saber. Em nosso tempo, cabe a ela revelar e sensivelmente esclarecer as complexas dimensões humanas de organização, expressão, significação, comunicação etc., conscienciosa de que seus aportes podem não ser descodificados imediatamente nos sistemas categóricos dispostos pelos investigadores. Além de sua criticidade. Dosse destaca que, às Ciências Humanas, fica a responsabilidade contínua de ampliar a ação cooperativa e dialogante entre leigos e cientistas, e também as possibilidades das esferas públicas política e científica para que a emancipação seja continuamente transversal entre saberes e povos.

\section{REFERÊNCIAS}

Ferreira, Marieta de Moraes. 2012. François Dosse. Revista Brasileira de História. 32 (64): 341-350. http://www.scielo.br/scielo.php?script=sci_arttext\&pid=S0102-01882012000200018\&lng=en\&nrm=iso

Dosse, François. 2018. O império do sentido: a humanização das Ciências Humanas. Trad. Ilka Stern Cohen. São Paulo: Editora Unesp. 